\title{
Congenital sialoblastoma of the accessory parotid gland
}

\author{
P Parag \\ Department of Radiology, Inkosi Albert Luthuli Central Hospital, Durban \\ P Parag, MB ChB, FCRad (D) SA
}

Corresponding author: P Parag (priyashinipar@ialch.co.za)

\begin{abstract}
Sialoblastomas are rare, locally aggressive, perinatal or congenital salivary gland tumours that mostly originate in the parotid gland. Significant variability in histological range and clinical course exists. This report is of a case of congenital sialoblastoma of the accessory parotid gland.
\end{abstract}

\section{S Afr J Rad 2012;16(4):134-135. DOI:10.7196/SAJR.751}

Sialoblastomas are rare salivary gland neoplasms that present congenitally or during early infancy, with significant variability in histological range and clinical course. ${ }^{1}$ In 1966, 2 cases were reported and referred to as embryomas. ${ }^{2}$ In 1988 , the term sialoblastoma was coined by Taylor to describe these lesions because it conveyed the dysontogenetic character and the site of the tumour. ${ }^{3}$ These tumours generally originate in the parotid gland but may arise in the submandibular or minor salivary gland. This report presents a case of congenital sialoblastoma of the accessory parotid gland.

\section{Case report}

A 3-day-old male neonate was referred with a large left facial mass with a provisional diagnosis of a teratoma. The baby was born at 35 weeks per normal vaginal delivery. Clinical examination revealed a $7 \mathrm{x} 8 \mathrm{~cm}$ solid mass over the left cheek with central ulceration. Dilated superficial blood vessels and facial distortion were noted. The mass was non-pulsatile. The rest of the physical examination was unremarkable.

MRI of the face with contrast was performed. A lobulated softtissue mass of the face was noted on the left with internal septations and foci of T1 hyperintensity. The mass extended to the inferior margin of the left orbit and laterally to the infratemporal fossa. Deviation of the nose to the left, absence of serpiginous flow voids and intense enhancement were noted. The parotid glands were normal. A diagnosis of haemangioma or sarcoma was considered. Subsequently, a biopsy was undertaken. The histological diagnosis was that of a sialoblastoma, placed in the WHO malignant category. Pre-operative chemotherapy was commenced and tumour shrinkage was observed over a 3-month period. A follow-up MRI was performed to aid surgical planning. The mass was significantly smaller and noted in close proximity to the superficial lobe of the left parotid gland. A diagnosis of congenital sialoblastoma of the accessory parotid gland was then made (Figs 1 - 3).

Complete excision of the tumour was performed and clear margins were confirmed on histology. The postoperative course was unremarkable and the baby was discharged after a week and closely followed up with no evidence of tumour recurrence. A 1-year surveillance MRI is being considered.

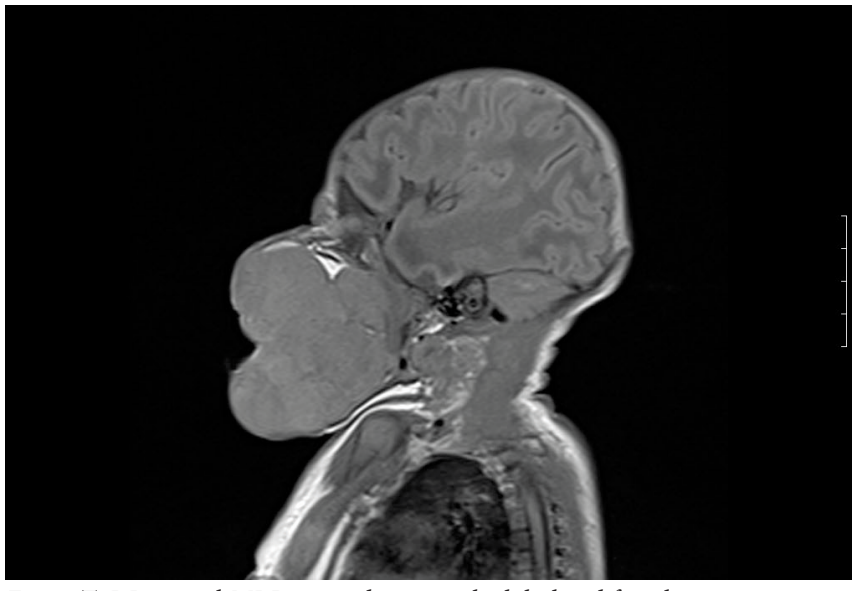

Fig. 1. T1W sagittal MRI image depicting the lobulated facial mass.

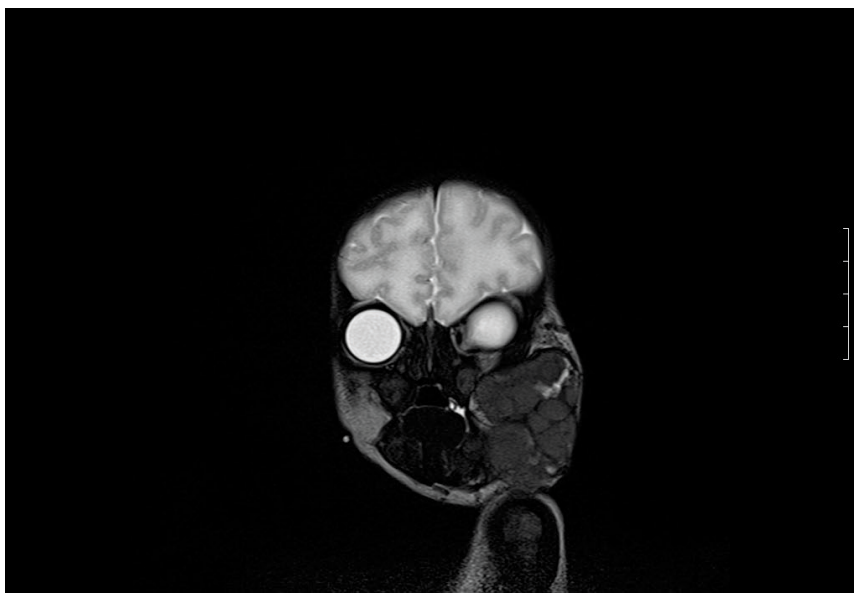

Fig. 2. T2W coronal fat-saturated MRI image showing the left facial mass with internal septations.

\section{Discussion}

Less than $3 \%$ of salivary gland tumours occur in children. ${ }^{4}$ The most common salivary gland lesion in childhood is a haemangioma. ${ }^{3}$ Sialoblastomas are rare, locally aggressive perinatal or congenital 


\section{CASE REPORT}

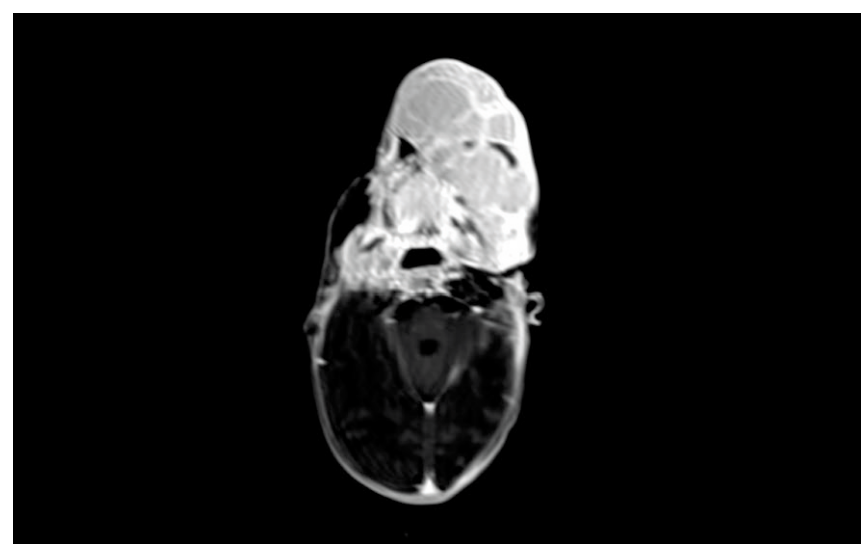

Fig. 3. T1W fat-saturated post-contrast axial image depicting intense enhancement of the mass.

salivary gland tumours that occur predominantly in the parotid gland ${ }^{3}$ and were initially classified as benign. ${ }^{1,3}$ The biological behaviour of this lesion is incompletely defined because of its rarity, and early surgery is recommended. ${ }^{3}$ In the literature, only 4 cases with lung metastases and 1 case with nodal neck metastases have been reported.
Surgical resection with negative margins is the mainstay of treatment, with some centres using neoadjuvant chemotherapy. ${ }^{5}$ Histologically, sialoblastomas appear as organoblasts in the primitive stage of salivary gland development. ${ }^{6}$ Typically, the tumours are iso-intense to muscle on T1, iso-intense to fat on $\mathrm{T} 2$, and enhance sparsely. ${ }^{3,4,6}$ In this case, the imaging characteristics and intense enhancement is atypical. Congenital haemangioma or fibrosarcoma are reasonable differential diagnoses in this case. ${ }^{4}$

1. Brandwein M, Al-Naeif NS, Manwani D, et al. Sialoblastoma: clinicopathological/immunohistochemical tudy. Am J Surg Pathol 1999;23:342-348.

2. Farooqi KM, Kessel R, Brandwein-Gensler M, Granowetter L, Manwani D. Sialoblastoma - long-term follow-up and remission for a rare salivary malignancy. Rare Tumors 2011;3(2):39-40.

3. Cristofaro M, Giudice A, Amentea M, Giudice M. Diagnostic and therapeutic approach to sialoblastoma of submandibular gland: a case report. J Oral Maxillofac Surg 2008;66(1):123-126.

4. Fuchsmann C, Viremouneix L, Collardeau-Frachon S, Bouvier R, Guibaud L, Froehlich P. Management and treatment of a sialoblastoma of the submandibular gland in a neonate: Report of one case. Int $\mathrm{J}$ Pediatr Otorhinolaryngol 2011;6(4):168-171. [http://dx.doi.org/10.1016/j.pedex.2010.07.001]

5. Xiao-Feng S, Zhi-Gang C, Jian-Guo Z, Jie Z, Yan G, Guang-Yan Y. Management of sialoblastoma with surgery and brachytherapy. Pediatr Blood Cancer 2010;55:1427-1430.

6. Som PM, Brandwein M, Silvers AR, Rothschild MA. Sialoblastoma (embryoma): MR findings of a rare pediatric salivary gland tumor. AJNR 1997;18(May):847-850. 